Provided for non-commercial research and education use. Not for reproduction, distribution or commercial use.

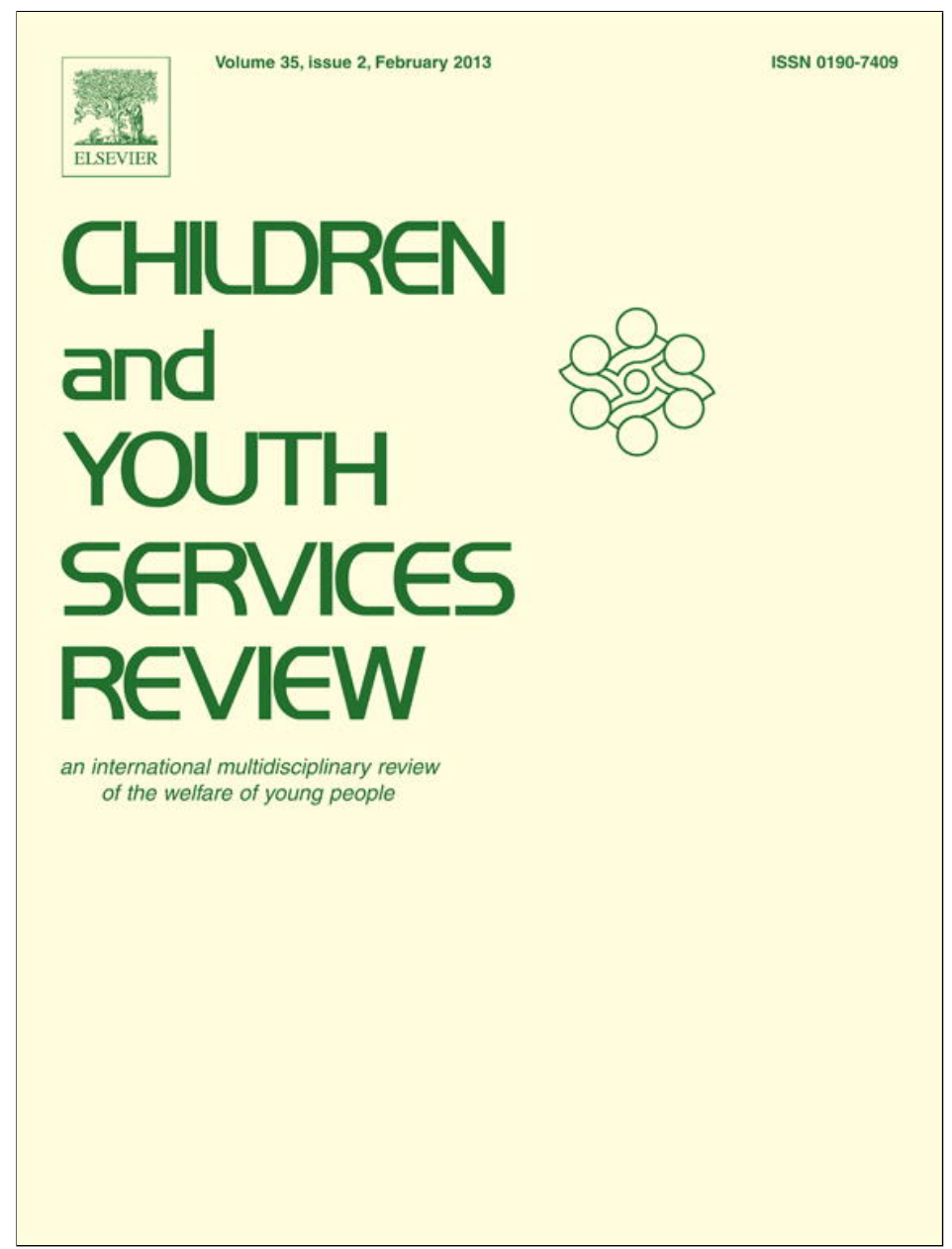

This article appeared in a journal published by Elsevier. The attached copy is furnished to the author for internal non-commercial research and education use, including for instruction at the authors institution and sharing with colleagues.

Other uses, including reproduction and distribution, or selling or licensing copies, or posting to personal, institutional or third party websites are prohibited.

In most cases authors are permitted to post their version of the article (e.g. in Word or Tex form) to their personal website or institutional repository. Authors requiring further information regarding Elsevier's archiving and manuscript policies are encouraged to visit:

http://www.elsevier.com/copyright 


\title{
Family group decision making: Measuring fidelity to practice principles in public child welfare
}

\author{
Mary Elizabeth Rauktis ${ }^{a}{ }^{*}$, Lauren Bishop-Fitzpatrick ${ }^{a}$, Nahri Jung ${ }^{a}$, Joan Pennell ${ }^{b}$ \\ a University of Pittsburgh, United States \\ ${ }^{\mathrm{b}}$ North Carolina State University, United States
}

\section{A R T I C L E I N F O}

\section{Article history:}

Received 11 October 2012

Accepted 8 November 2012

Available online 19 November 2012

\section{Keywords:}

Family group decision making

Model fidelity scale

Implementation evaluation

\begin{abstract}
A B S T R A C T
This study describes the development and validation of a short, self-administered fidelity measure used to capture the perspectives of a range of individuals participating in a family group decision making conference. Exploratory factor analyses suggested either a two or a three factor solution. Findings from confirmatory factor analysis supported a three factor model that includes sets of practices yielding: (1) Productive Decision Making; (2) Family Group Inclusion; and (3) Professional Supportiveness. These results provide direction to public child welfare practitioners and policymakers about the importance and the feasibility of attending to multiple perspectives in assessing program delivery.
\end{abstract}

(c) 2012 Elsevier Ltd. All rights reserved.

\section{Introduction}

Increasingly, public child welfare systems in the United States and other countries seek to engage family groups in decision making about their young relatives (Pennell, Burford, Connolly, \& Morris, 2011). This means that workers reach beyond the immediate family to include their relatives and "social" kinship network in making and implementing plans. The practice assumption is that children in need of protection are better off if their family group takes responsibility for their welfare in partnership with public agencies and community organizations. The guiding principles are that children and their families have the right to make decisions over their affairs and that children have a right to remain connected to their cultural heritage (United Nations, 2007, 1989).

Although family group engagement is compelling both ethically and conceptually (Barth, 2002; Burford, Pennell, \& Edwards, 2011; Crampton, 2007), additional research is needed to conclusively establish its efficacy in terms of child safety, permanence, and well-being (Shlonsky et al., 2009). A critical element in establishing efficacy is to first determine model fidelity in order to make the connection between service programs and their outcomes (Mowbray, Holter, Teague, \& Bybee, 2003). Because family group engagement models are based on tenets of human rights and cultural respect, fidelity in this context is defined as to whether "an intervention is carried out in a manner that is true to its key principles and their practices" (Pennell, 2005, p. 110, emphasis in original). A confounding factor in assessing the fidelity of family group practice is that child welfare,

\footnotetext{
* Corresponding author.

E-mail address: mar104@pitt.edu (M.E. Rauktis).
}

especially in the United States, has adopted a range of models. These go variously by such names as family group decision making, family group conferencing, family team meetings, family unity meetings, and team decision making (Merkel-Holguin \& Wilmot, 2005). Moreover, how agencies carry out a particular family group model is not necessarily consistent with its central features.

Hayes (1998) predicted that one of the biggest challenges in the adoption of evidence-based practices would be measuring fidelity quickly and efficiently, and this was confirmed thirteen years later by Schoenwald et al. (2011). A lack of attention to core family group principles can lead to unintended "drift" in practice (Breitenstein et al., 2010; Crea, Crampton, Abramson-Madden, \& Usher, 2008; Rauktis, Huefner, \& Cahalane, 2011a). However, the fidelity measures for family group models described in the research literature usually require timeintensive activities such as reviewing records and plans (Stuczynski \& Kimmich, 2010; Vesneski \& Kemp, 2000) or phone interviews (Pennell, 2005), or they have been created for research studies and used only with small samples (Berzin, Thomas, \& Cohen, 2007). There is a need for a psychometrically sound family group fidelity measure that is both based on principles and implemented in the real-world context of child welfare practice.

The purpose of this paper is to describe the development and validation of a short, self-administered fidelity measure that captures the perspectives of multiple informants at the conference and that can be used to improve practice in public child welfare. The study took place in Pennsylvania where nearly all county child welfare agencies had adopted the model of family group decision making (FGDM; Rauktis et al., 2011a). These agencies agreed to participate in a statewide survey that was conducted by the University of Pittsburgh to measure model fidelity. The authors begin by examining different approaches to measuring model fidelity and reviewing the 
North Carolina instrument (Pennell, 1999) on which the Pennsylvania survey was based. Turning to developments in Pennsylvania, the authors describe the state's FGDM model and the process of refining the survey to fit the local context. Next they describe the sample of 5456 usable surveys and the data analyses used to explore and then confirm the factor structure of the FGDM model fidelity scale. The results yielded three reliable FGDM subscales measuring the extent of Productive Decision Making, Family Group Inclusion, and Professional Supportiveness. The conclusions discuss the importance of incorporating model fidelity measures into public child welfare in order to uphold agency accountability for family group engagement in decision making.

\subsection{Measuring model fidelity}

Several theoretical approaches have been used in developing fidelity measures. One approach is founded on the assumption that programs consist of essential elements that can be operationalized into variables and indicators that then determine whether a program is present or absent (Hall \& Hord, 1987). Another approach is to measure the structure or framework of a program as well as the human interactions or processes that occur in its delivery (e.g., structure and process approach; Mowbray et al., 2003). Finally, there is also a hybrid of both of these approaches which combines elements of measuring and operationalizing the essential program elements and elements of the human interactions or processes that occur in the delivery of the model (Century, Rudnick, \& Freeman, 2010). Regardless of the methodology, the research is fairly consistent in recommending the ongoing monitoring of fidelity in order to ensure high quality (Fixsen, Naoom, Blasé, Friedman, \& Wallace, 2005). Not surprisingly, a review of the implementation literature verifies that fidelity has been measured more often than any other implementation outcome (Proctor et al., 2011).

Several developers have devoted considerable effort to constructing treatment fidelity tools, and these metrics are present across different models and service systems. For example, the developers of Multisystemic Therapy (MST) created adherence tools based upon practice principles in order to offer clarity about the model without inhibiting the necessary responsiveness to local conditions (Henggeler, Schoenwald, Borduin, Rowland, \& Cunningham, 1998). These tools could be applied by MST supervisors and consultants in monitoring treatment adherence (Henggeler, Borduin, Schoenwald, Huey, \& Chapman, 2006). In addition, self-administered client fidelity measures for MST were also created so that the caregiver perspective of fidelity could be assessed (Schoenwald et al., 2011). The fidelity to Assertive Community Treatment (ACT) scale was developed due to concerns about the contradictory results being reported by replication sites (Teague, Bond, \& Drake, 1998). Furthermore, wraparound, the intervention most equivalent to FGDM has used the Wraparound Fidelity Index to measure the quality of wraparound implementation from the perspectives of the children's caregivers and the program facilitators (Bruns, Burchard, Suter, Leverentz-Brady, \& Force, 2004).

Fidelity measures have also been shown to be related to program or model outcomes in a number of different contexts. For instance, implementation studies of MST have found that MST treatment adherence is strongly related to favorable outcomes such as improved symptomatology and decreased incarceration (Henggeler, Melton, Brondino, Scherer, \& Hanley, 1997; Schoenwald, Henggeler, Brondino, \& Rowland, 2000). Similarly, positive outcomes, such as reductions in substance abuse and fewer hospital stays for individuals with severe mental illness who were enrolled in ACT programs, were strongly and significantly related to a program's fidelity (McHugo, Drake, Teague, \& Xie, 1999). Finally, implementation studies using the Wraparound Fidelity Index found a relationship between model adherence and favorable child and family outcomes (Bruns, Suter, Force, \& Burchard, 2005; Rast,
Peterson, Earnest, \& Mears, 2003). As such, model fidelity may play a very large role in the achievement of positive treatment outcomes.

\subsection{Measuring fidelity to critical components of family group decision making}

The family group decision making (FGDM) model used in Pennsylvania is based on the New Zealand model of family group conferencing. The practice of family group conferencing was first legislated in New Zealand after protests by Indigenous people against Euro-centric approaches to child welfare and youth justice that were experienced as undermining to their kinship networks (Rangihau, 1986). The 1989 New Zealand legislation upheld the responsibilities of the family group for their young relatives, children's rights to safety and to making decisions over their lives, the importance of children's culture, and community-state collaboration (Hassall, 1996). The model was instituted across the country for child protection matters that would otherwise have been resolved in the court, and coordinator positions were established to organize and convene the conferences.

Family group conferencing and variations of the model were adopted by child welfare systems around the globe (Burford, Connolly, Morris, \& Pennell, 2010; Rotabi, Pennell, Roby, \& Bunkers, 2012). The term family group decision making was coined for an early Canadian demonstration project of the New Zealand model in situations of family violence (Pennell \& Burford, 1995) and later used in the United States to refer to family group conferencing applied in child welfare (American Humane Association \& FGDM Guidelines Committee, 2010). Feedback from the families and professionals was overwhelmingly positive, with high levels of satisfaction reported (Bell \& Wilson, 2006; Crampton \& Jackson, 2007; Crea \& Berzin, 2009; Pennell \& Anderson, 2005; Pennell \& Burford, 2000; Sheets et al., 2009; Sieppert, Hudson, \& Unrau, 2000). However, the evidence on the effectiveness of family group models in preventing reoccurrence of maltreatment and improving permanence has been conflicting (e.g., Berzin, 2006; Berzin et al., 2007; Pennell \& Burford, 2000; Pennell, Edwards, \& Burford, 2010; Sheets et al., 2009; Sundell \& Vinnerljung, 2004; Weigensberg, Barth, \& Guo, 2009). Without assurance of fidelity to a model, it cannot be determined if the results are due to an ineffective model or to faulty implementation.

\subsection{Intervention model principles}

Given the importance of model fidelity to understanding outcomes achieved in different contexts, key principles needed to be established in order to give direction to family group conferencing and to examine model fidelity (Pennell, 2003b). Based on her work in Canada (Pennell \& Burford, 1995), Joan Pennell (1999) conceptualized the model as a series of nine principles: (1) build broad-based support and cultural competence; (2) enable the coordinators to work with family groups in organizing their conferences; (3) have the conference belong to the family group; (4) foster understanding of the family and creativity in planning; (5) help the conference participants take part safely and effectively; (6) tap into the strengths of the family group in making the plan; (7) promote carrying out the plan; (8) fulfill the purpose of the plan; and (9) change policies, procedures and resources to sustain partnerships among family groups, community organizations and public agencies. Based on these principles, activities that should occur before, during, and after the family group meeting were then established. For example, the principle "have the conference belong to the family" is operationalized as meeting with family members prior to the conference to explain the purpose of the meeting, select its venue, and create a list of individuals to invite.

To check for practice integrity, Pennell next developed and tested in North Carolina a measure of adherence to these principles. This instrument, called the "Achievement of Family Group Conferencing (FCG) Objectives" (Pennell, 2003a), operationalized the principles into a series of 
questions about activities associated with the conference preparations, the meeting participation, and the resulting plan of action. A separate scale examined the post-conference work. In the Achievement of FGC Objectives measure, the family group conference became the object of fidelity. For example, the principle "have the conference belong to the family group" is assessed by the item "more family group members than service providers were invited to the conference." For each of the items, the respondent is asked to give an answer of strongly disagree, disagree, agree, or strongly agree, with the additional options of don't know and not applicable.

The Achievement of FGC Objectives metric was completed with relative ease by family group members through a telephone interview, on average one month after the conference. A study of 151 respondents from 30 conferences found that the Achievement of FGC Objectives yielded ratings congruent with qualitative analyses of coordinators' documentation of their preparations and the conference proceedings, participants' narratives of their conference, and researchers' observations of the conference deliberations; and the scale succeeded in identifying the convergences and divergences in viewpoints of family and service providers and had strong internal consistency (Pennell, 2005).

Exploratory factor analyses (Pennell, 2004) identified three subscales: cultural safety (conference held in the right way for the family group), community partnerships (family group and service providers are clear about what they are doing), and family leadership (family group empowered to make a plan) (Pennell, 2009). Canonical correlation analysis of the FGC Evaluations (a participant satisfaction form) completed immediately at the conclusion of the conference and the Achievement of FGC Objectives identified a fourth FGC Objectives subscale of inclusive planning (diverse family participants involved, and continued family-community-state planning supported) (Pennell, 2006, 2009). Fig. 1 below displays the practice principles, FGC objectives, and four FGC objectives subscales.

As previously noted, creating measures that are psychometrically sound and that can be implemented in everyday practice presents multiple challenges (Schoenwald et al., 2011). Fidelity monitoring is a critical need in child welfare because it ensures that evidence-based and promising practices are implemented as intended in real-world contexts (Kaye \& Osteen, 2011). When FGDM is part of a clinical trial or a program evaluation, it is more likely that there are dedicated resources for interviewing family members, viewing and coding video or audiotapes, and using fidelity measures than when it is part of the typical services. However, states, counties, tribes, and provinces rarely have the resources and expertise to routinely monitor fidelity.

Although the Achievement of Family Group Conferencing (FCG) Objectives scale was promising and available free of charge, the administration method made it less likely to be used by public child welfare agencies. A multi-informant measure of fidelity to family group decision making was needed that could be self-administered by a variety of family, friends, and professionals, and used to guide implementation of practice. To address this gap, the current study aimed to revise and to examine the factor structure of a self-administered version of the Achievement of FGC Objectives scale. This was a 3-year development project undertaken by the Pennsylvania Office of Children Youth and Families and the University of Pittsburgh, Child Welfare Resource center and approved by the University of Pittsburgh Institutional Review board. This study fills a critical gap in the field of child welfare practice by testing both the psychometric qualities of the scale as well as the feasibility of broadly monitoring fidelity.

\section{Method}

\subsection{Procedure}

\subsubsection{Context}

In Pennsylvania, the process begins with a referral of the family to FGDM by the caseworker. The FGDM coordinator then meets with the parents/caregivers, describes the purpose and process of FGDM, explains the roles of the other participants, clarifies expectations, and obtains agreement. The next phase, preparation, involves the coordinator and the parent working together to identify who should be invited to the conference, what the objectives for the FGDM conference will be, where the conference will take place, and when it will happen. A search is undertaken to widen the circle by contacting kin and other informal supports or reviewing files in order to obtain information about people who once played an important role in their lives, but with whom they have lost contact. The FGDM coordinator may then become the FGDM facilitator at the meeting, or a different professional may serve as the conference facilitator who is responsible for convening and organizing the deliberations. The meeting has four phases: (1) a welcome/ introduction; (2) information sharing; (3) private family time in order for the family group to create a plan without the service providers present; and (4) acceptance and finalizing the plan and then closing the meeting. When the family is done meeting privately, they present their plan for the care and protection of the children. The plan is reviewed; if approved, then it is determined how the plan will be implemented and monitored, and which individuals will assist the family to secure needed services and resources.

In the past, at the end of every conference a satisfaction survey was distributed, completed by the members, and then returned to the resource center. However, there were some indications of practice inconsistencies such as inadequate preparation of professionals and inconsistent follow through (Rauktis, 2008). As a result, participating child welfare agencies agreed to assess model fidelity by administering the Achievement of FGC Objectives scale. The instrument was revised to reflect practices specific to Pennsylvania and to accommodate selfadministration.

\subsubsection{Initial revisions}

The revision process of the scale is described in greater detail elsewhere (Rauktis, Pennell, Burford, Crampton, \& Merkel-Holguin, 2012; Rauktis, Pennell, \& Reinhart, 2011b; Rauktis et al., 2011a). For the revision, new instructions, re-formatting, and demographic questions were created and, at the request of the Office of Children Youth and Families, two new items were included: "the children will be safer as a result of this plan" and "I would recommend family group to other families." After an initial period of six months of data collection, however, it became apparent that there were problems. There was unanimous dislike of the look and feel of the measure which had a format similar to standardized tests. Families felt that the language was confusing: the family group became the focus or object to be rated rather than the individual. For example, "The family group had private time to make the plan" rather than "I had private time with our family in order to make the plan." The individuals who were facilitating and coordinating the groups also were concerned about how the information would be used.

Satisfaction ratings in the past had been uniformly high, and the rationale for fidelity monitoring had not been widely communicated to all of the stakeholders. A series of conference calls were conducted with all of the FGDM coordinators and facilitators in order to clarify the purpose, determine their concerns, and solicit suggestions for improving the measure as well as the process of administering the survey. When the purpose was identified as improving the quality of FGDM, there was greater cooperation and less resistance to measuring fidelity. The FGDM professionals felt that some of the language was confusing, and cognitive interviews conducted with family members identified language that was likely causing measurement error. Descriptive analyses revealed a large number of missing responses on certain items and improperly completed surveys suggested additional problems (Rauktis et al., 2011b). Subsequently, six items were revised to simplify language and to be more consistent with the model of FGDM used in Pennsylvania. The demographics were revised and moved to the end, and a new scanning application resulted 
in a more "family friendly" format. Detailed instructions were created for the individuals who distributed the surveys along with a simplified set of instructions for the families. The professionals felt that since FGDM "began with strengths," the responses should be re-ordered; responses were revised to go from positive to negative-Strongly Agree, Agree, Disagree, and Strongly Disagree. However, the "family group" remained the object to be rated; the professionals believed that if some of the terms were simplified, this would reduce the confusion caused by the objectification of the group process. This revision was piloted, and the results for 703 surveys collected from 98 conferences revealed good internal consistency (alpha coefficient $=.93$ ), and there were less missing data. When compared to the averages from the earlier version, the revision produced similar average scores, but with smaller ranges and standard deviations (Rauktis et al., 2011b). This revision was called the family group decision making model fidelity scale or the FGDM-MFS.

\subsection{Sample}

Data for the present analysis came from public child welfare agencies in Pennsylvania during a ten month period in 2010 and 2011. A total of 8889 surveys were completed and submitted during a ten-month period. Of this total, 1575 could not be scanned or entered for several reasons. For example, some were missing the relationship to the child, others were completed using the earlier form version, and others had a third or more missing information. The 7314 surveys were then examined for problems with response bias, i.e., all 17 items endorsed using the same exact response pattern. This review resulted in 5456 usable surveys. Of those surveys, $17 \%$ were completed by parents, $6 \%$ were completed by youth, $33 \%$ were completed by relatives, and $9 \%$ were completed by friends. Professionals from mental health, drug and alcohol, and other systems were $13 \%$ of the respondents and CYS professionals represented $14 \%$. Finally, the remainder (8\%) classified themselves as "other."

To allow for both an exploratory factor analysis (EFA) and a confirmatory factor analysis (CFA), the analytic sample was randomly and evenly divided into two subsamples of 2728 participants each. Table 1 displays the socio-demographic information for the subsamples categorized according to the type of analysis (EFA or CFA). Across four demographic variables-respondents' age, gender, race, or relationship to the child for whom the conference was convened-no significant differences existed between the EFA and CFA subsamples.

\subsection{Data analyses}

The responses to the 17 items from the FGDM-MFS provided by the first random half of 2728 participants were subjected to an exploratory factor analysis applying an oblique rotation using the SPSS 19.0 statistical package. This exploratory factor analysis was conducted to identify the factor structure for fidelity to the FGDM model. Both the Kaiser-Meyer-Olkin test and Barrett's sphericity tests are used to confirm the appropriateness of the provided factor models. Then, Cattell's (1966) scree test was used to ascertain the correct number of dimensions to extract. Items were assigned to factors based on their highest loading (minimum acceptable loading of 40). Each factor model for which factors were fixed as suggested by the scree plot was examined in order to select the final model by investigating the pattern matrix and theoretical validation of the factor model.

After developing an initial factor structure based on the EFA for the first half of the data $(n=2728)$, a CFA was used on data from the second half of participants $(n=2728)$ in order to compare model fit for the two competing models suggested by the exploratory factor analysis using the EQS 6.0 statistical package. Chi-square difference tests were conducted in order to assess the relative advantage of each factor model suggested by the exploratory factor analysis.
Table 1

Characteristics of sample.

\begin{tabular}{llll}
\hline Variable & EFA group & CFA group & $p$ \\
\hline Age range, $n$ (\%) & $n=2439^{\mathrm{a}}$ & $n=2445$ & .205 \\
$13-17$ years old & $229(9.34)$ & $210(8.59)$ & \\
$18-21$ years old & $148(6.07)$ & $129(5.28)$ & \\
$22-30$ years old & $493(20.21)$ & $535(21.88)$ & \\
$31-40$ years old & $587(24.07)$ & $558(22.82)$ & \\
$41-50$ years old & $453(18.58)$ & $478(19.55)$ & \\
$51-60$ years old & $333(13.65)$ & $329(13.46)$ & \\
61-70 years old & $140(5.74)$ & $147(6.01)$ & \\
Over 70 years old & $56(2.30)$ & $59(2.41)$ & .966 \\
Gender, $n$ (\%) & $n=2436^{\mathrm{a}}$ & $n=2434$ & \\
Male & $745(30.59)$ & $743(30.53)$ & \\
Female & $1691(69.42)$ & $1691(69.47)$ & \\
Race, $n$ (\%) & $n=2388$ & $n=2385$ & .733 \\
European American & $1763(73.83)$ & $1697(71.15)$ & \\
African American & $463(19.39)$ & $506(21.22)$ & \\
Asian/Pacific Islander & $5(.21)$ & $5(.21)$ & \\
Native American/Alaskan/Hawaiian & $7(.29)$ & $18(.75)$ & \\
Multiracial & $77(3.22)$ & $68(2.85)$ & \\
Other & $73(3.06)$ & $91(3.82)$ & \\
Relationship, $n$ (\%) & $n=2724^{\mathrm{a}}$ & $n=2717^{\mathrm{a}}$ & .968 \\
Child & $163(5.98)$ & $151(5.56)$ & \\
Parent & $469(17.22)$ & $454(16.71)$ & \\
Other relative & $865(31.75)$ & $886(32.61)$ & \\
Friend & $254(9.32)$ & $253(9.31)$ & \\
Professional & $331(12.15)$ & $364(13.40)$ & \\
CYS & $388(14.24)$ & $352(12.96)$ & \\
Other & $254(9.32)$ & $257(9.46)$ & \\
\hline a Percentage & & & \\
& & & \\
& & &
\end{tabular}

a Percentage does not add up to 100 due to rounding error.

The model fit indices for each factor model are also reported. These include: (1) the comparative fit index (CFI); (2) the root mean square error of approximation (RMSEA); and (3) the standardized root mean square residual (SRMR). For RMSEA and SRMR, values less than 05 represent good fit. For CFI, a value greater than 95 is considered consistent with a good model fit (Bentler, 1990; Stevens, 1996). Internal consistency (Chronbach's alpha) for the FGDM-MFS is also reported for the entire sample.

\section{Results}

An EFA was conducted to explore the latent factor structure for the first random sample of respondents, ages 13 and older. Because of the missing data on several items, all three approaches to managing missing data (listwise, pairwise, and meansub) were considered but listwise deletion was used because it is the most conservative approach. Before conducting the EFA, several statistical assumptions were checked. The Kaiser-Meyer-Olkin measure of sampling adequacy was 936, and the Bartlett's test of sphericity was statistically significant $\left(\chi^{2}=9310.148, d f=136, p<.001\right)$. The EFA was conducted with an oblique (oblimin) rotation and a principal components extraction. A scree test and Eigenvalues of 1.0 and greater were used to decide the number of factors, and items with a pattern coefficient of greater than 40 were considered to load on a factor. One item, Question 13 , loaded on Factor 3, but the value was slightly less than 40 (.33). Table 2 displays the three-factor solution which accounted for $53.632 \%$ of the total variance.

The ten items that load on Factor One encompass the preparation for the family group conference including an understanding of the roles and how the group process was conducted, including cultural sensitivity and assurance of safety for the members. Items about the outcome of the meeting, namely the plan and follow-up steps also loaded on this factor. The three items about who came to the conference and the ratio of professionals to family loaded on Factor Two: "more family than professionals," "different sides of the family," and "people at the conference were relatives or like family." Finally, 
Table 2

EFA factor loadings: three-factor solution $(n=2728)$

\begin{tabular}{|c|c|c|c|}
\hline Item & Factor $1 \mathrm{P}$ & Factor $2 \mathrm{P}$ & Factor $3 \mathrm{P}$ \\
\hline \multicolumn{4}{|l|}{ Factor 1} \\
\hline Q16: The plan included steps to evaluate if the plan is working and to get the family group back together again if needed. & .823 & .051 & -.147 \\
\hline Q15: The plan included ways that the family group will help out. & .708 & .161 & .049 \\
\hline Q10: The family group was prepared for the conference(ex. got enough information on what happens at a conference) & .701 & .004 & .067 \\
\hline Q17: The plan was approved quickly. & 696 & -.028 & -.151 \\
\hline Q11: The paid professionals were prepared for the conference (ex. got enough information on what happens at a conference). & .599 & .048 & .247 \\
\hline Q12: The conference had enough supports and protections (ex. support persons) & .588 & .179 & .109 \\
\hline Q6: The conference was held in a way that felt right to the family group (ex. the right food, right time of day). & .537 & -.084 & .348 \\
\hline Q14: The family group had private time to make their plan. & .514 & .213 & .196 \\
\hline Q4: The family group understood the reasons for holding the conference. & .504 & -.132 & .351 \\
\hline Q5: The conference was held in a place that felt right to the family group. & .461 & -.048 & .411 \\
\hline \multicolumn{4}{|l|}{ Factor 2} \\
\hline Q7: More family group than paid professionals participated in the conference. & -.087 & .782 & .128 \\
\hline Q8: Different sides of the family participated in the conference (ex. father and mother sides of the family). & .083 & .744 & -.147 \\
\hline Q9: People at the conference were relatives and/or people who feel "like family" (ex. old friends, good neighbors). & .306 & .510 & .143 \\
\hline \multicolumn{4}{|l|}{ Factor 3} \\
\hline Q3: The FGDM facilitator/coordinator did not have other jobs to do with the family beside organizing and/or facilitating the group. & -.168 & .119 & .783 \\
\hline Q2: The FGDM facilitator was respectful of the family group. & .102 & -.019 & .727 \\
\hline Q1: Each paid professional was clear about their role (ex. child protection, counseling). & .195 & -.074 & .646 \\
\hline Q13: Paid professionals shared their knowledge but they did not tell the family group how to solve the concerns. & .139 & .165 & .334 \\
\hline
\end{tabular}

$\mathrm{P}=$ pattern.

Bold items refer to factor loading of the item in the factor to which it was extracted at 40 or greater. An exception to this is Q13 which had a factor loading of 334 and is bolded and in italics.

the four items that loaded onto Factor Three were specific to how the professionals conducted themselves before and during the conference. These items referred to role clarity, respectfulness and recognition of the family's knowledge, and the focus of the coordinator on the family group rather than on the investigation or other activities. The three factors were correlated, with the correlation coefficient between Factor One and Factor Three the strongest $(r=.483)$, and a moderate correlation between Factor One and Factor Two $(r=.306)$. The correlation between Factor Two and Factor Three was the lowest $(\mathrm{r}=.222)$.

Because the correlation between Factor One and Factor Three was moderate, another EFA with an oblique rotation was conducted. This second EFA solution specified two factors to see if a more parsimonious factor structure would be possible. This solution explained slightly less variance (47.448\%). The results can be viewed in Table 3. The items that previously loaded on Factor Three regarding the professional's role now loaded on Factor One, with the same three items about who came to the conference remaining on Factor Two. Question 13 had a higher pattern coefficient (.41).

In order to ascertain whether the two or three factor solution was a better fit to the data, a CFA was performed. Results of the CFA indicated that ten items loaded onto Factor One, three items loaded onto Factor Two, and four items loaded onto Factor Three (Fig. 1; Table 4). These results mirrored the results found under the three-factor solution produced by the EFA. The data were not multivariate normal, $z=$ $86.88, p<.001$. As such, maximum likelihood with robust adjustments (Satorra \& Bentler, 1988, 1994) was used.

There was a significant difference between the observed and modeled covariance matrix, likely due to the large sample size: Satorra-Bentler $\chi^{2}(116, N=2728)=787.057, p<.001$. The model fit was poor; $\mathrm{CFI}=.898, \mathrm{RMSEA}=.064$. As such, according to Lagrange Multiplier Test, the model was modified by adding a correlated error

Table 3

EFA factor loadings: two-factor solution $(n=2728)$.

\begin{tabular}{|c|c|c|}
\hline Item & Factor $1 \mathrm{P}$ & Factor $2 \mathrm{P}$ \\
\hline \multicolumn{3}{|l|}{ Factor 1} \\
\hline Q6: The conference was held in a way that felt right to the family group (ex. the right food, right time of day). & .765 & -.072 \\
\hline Q5: The conference was held in a place that felt right to the family group. & .755 & -.065 \\
\hline Q4: The family group understood the reasons for holding the conference. & .739 & -.123 \\
\hline Q1: Each paid professional was clear about their role (ex. child protection, counseling). & .735 & -.188 \\
\hline Q11: The paid professionals were prepared for the conference (ex. got enough information on what happens at a conference). & .731 & .087 \\
\hline Q2: The FGDM facilitator was respectful of the family group. & .727 & -.171 \\
\hline Q10: The family group was prepared for the conference(ex. got enough information on what happens at a conference) & 658 & .104 \\
\hline Q15: The plan included ways that the family group will help out. & .650 & .258 \\
\hline Q14: The family group had private time to make their plan. & .614 & .241 \\
\hline Q12: The conference had enough supports and protections (ex. support persons) & .600 & .242 \\
\hline Q16: The plan included steps to evaluate if the plan is working and to get the family group back together again if needed. & .574 & .218 \\
\hline Q3: The FGDM facilitator/coordinator did not have other jobs to do with the family beside organizing and/or facilitating the group. & .547 & -.097 \\
\hline Q17: The plan was approved quickly. & .462 & .123 \\
\hline Q13: Paid professionals shared their knowledge but they did not tell the family group how to solve the concerns. & .414 & .102 \\
\hline \multicolumn{3}{|l|}{ Factor 2} \\
\hline Q8: Different sides of the family participated in the conference (ex. Father \& Mother sides of the family). & -.052 & .754 \\
\hline Q7: More family group than paid professionals participated in the conference. & .046 & 699 \\
\hline Q9: People at the conference were relatives and/or people who feel "like family" (ex. old friends, good neighbors). & .392 & .501 \\
\hline
\end{tabular}

$\mathrm{P}=$ pattern.

Bold items refer to factor loading of the item in the factor to which it was extracted at 40 or greater. 


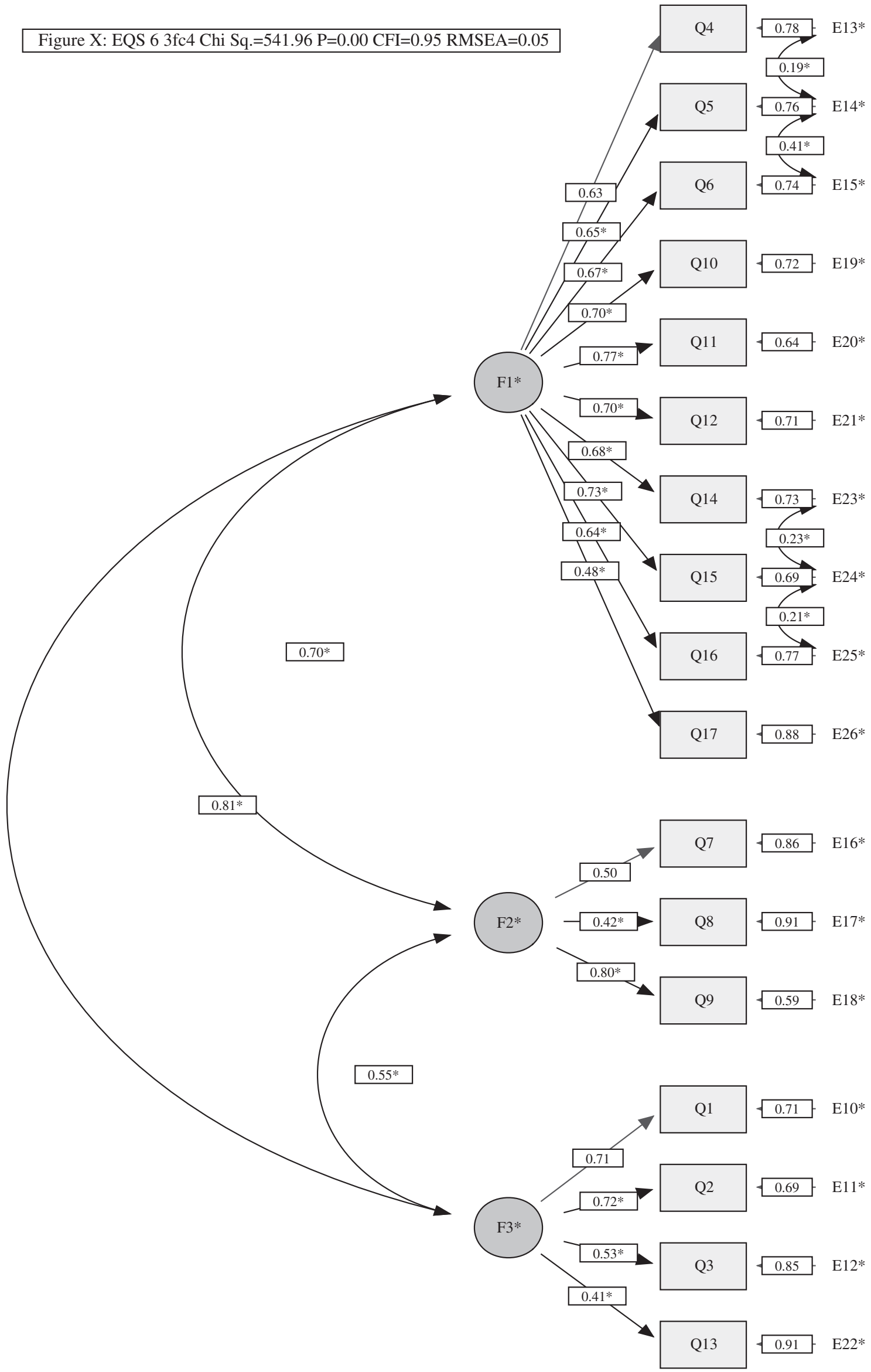

Fig. 1. Standardized factor loadings and error terms for each item in the CFA. *Significant at the $p<.05$ level. 
Table 4

CFA factor loadings: three factor solution.

\begin{tabular}{|c|c|c|c|c|c|c|c|c|}
\hline \multicolumn{4}{|l|}{ Path } & \multicolumn{5}{|c|}{ Robust } \\
\hline & & & $B$ & $\bar{\beta}$ & SE & $\mathrm{z}$ & $p$ & $R^{2}$ \\
\hline Q4 & $\leftarrow$ & $\mathrm{F} 1$ & 1.000 & .627 & & & & .394 \\
\hline Q5 & $\leftarrow$ & & $1.017^{\mathrm{a}}$ & .648 & .043 & 23.489 & $<.001$ & .420 \\
\hline Q6 & $\leftarrow$ & & $1.066^{\mathrm{a}}$ & .668 & .046 & 23.097 & $<.001$ & .447 \\
\hline Q10 & $\leftarrow$ & & $1.217^{\mathrm{a}}$ & .699 & .053 & 23.067 & $<.001$ & .489 \\
\hline Q11 & $\leftarrow$ & & $1.167^{\mathrm{a}}$ & .768 & .049 & 23.776 & $<.001$ & .589 \\
\hline Q12 & $\leftarrow$ & & $1.154^{\mathrm{a}}$ & .700 & .053 & 21.916 & $<.001$ & .491 \\
\hline Q14 & $\leftarrow$ & & $1.063^{\mathrm{a}}$ & .684 & .052 & 20.532 & $<.001$ & .468 \\
\hline Q15 & $\leftarrow$ & & $1.124^{\mathrm{a}}$ & .726 & .052 & 21.429 & $<.001$ & .527 \\
\hline Q16 & $\leftarrow$ & & $1.156^{\mathrm{a}}$ & 641 & .056 & 20.593 & $<.001$ & .411 \\
\hline Q17 & $\leftarrow$ & & $.944^{\mathrm{a}}$ & .479 & .058 & 16.345 & $<.001$ & .230 \\
\hline Q7 & $\leftarrow$ & & 1.000 & .505 & & & & .255 \\
\hline Q8 & $\leftarrow$ & F2 & $.927^{\mathrm{a}}$ & .420 & .072 & 12.946 & $<.001$ & .176 \\
\hline Q9 & $\leftarrow$ & & $1.169^{\mathrm{a}}$ & .804 & .072 & 16.239 & $<.001$ & .647 \\
\hline Q1 & $\leftarrow$ & & 1.000 & .708 & & & & .502 \\
\hline Q2 & $\leftarrow$ & & $.857^{a}$ & .723 & .038 & 22.501 & $<.001$ & .522 \\
\hline Q3 & $\leftarrow$ & F3 & $.991^{\mathrm{a}}$ & .528 & .050 & 19.962 & $<.001$ & .279 \\
\hline Q13 & $\leftarrow$ & & $.856^{\mathrm{a}}$ & .414 & .055 & 15.557 & $<.001$ & .172 \\
\hline
\end{tabular}

a Significant at the $p<.05$ level.

of E14 and E15, E23 and E24, E24 and E25, and E13 and E14. After modification, the model fit improved substantially; Satorra-Bentler $\chi^{2}(112$, $N=2728)=438.693, p<.001, \mathrm{CFI}=.950, \mathrm{RMSEA}=.045$.

The CFA suggests that a three factor model is a better fit than the two factor model. The correlations between the factors were in the high to moderate range, with the highest correlation observed $(.81)$ for Factor 1 and Factor 2 and the lowest (.55) between Factors 2 and 3.

\section{Discussion}

\subsection{Conceptualization of the FGDM-MFS subscales}

The exploratory factor analysis yielded a three factor solution that was supported by the confirmatory factor analysis. The ten items that load on Factor One encompass (a) the preparation for the family group conference with attention to role clarity, cultural sensitivity, and participant safety and (b) the content of the plan and its expeditious approval. The resulting subscale can be conceptualized as Productive Decision Making in that all its ten items contribute to a successful planning process and quality plans. The three items about who came to the conference and the ratio of professionals to family loaded on Factor Two: "more family than professionals," "different sides of the family," and "people at the conference were relatives or like family." These can be conceptualized as a Family Group Inclusion subscale in that these practices foster a conference which weights participation toward the larger family group and away from professionals. Finally, the four items that loaded onto Factor Three were specific to how the professionals conducted themselves before and during the conference. These items referred to the professionals' role clarity and their respectfulness and recognition of the family's knowledge and to the focus of the FGDM facilitator on the conference process rather than on other jobs such as case management. The subscale can be termed Professional Supportiveness in that each practice encouraged a context in which service providers reinforced the leadership of the family group.

\subsection{Incorporating measures of model fidelity into public child welfare}

This study aimed to develop and test a principle-based measure of fidelity for FGDM that could be self-administered after a conference in order to capture the perspectives of multiple group members. The findings supported a three factor model that includes sets of practices yielding: (1) Productive Decision Making-a successful planning process and quality plans; (2) Family Group Inclusion-weighing participation toward the larger family group and away from professionals; and (3) Professional Supportiveness-service providers reinforcing the leadership of the family group. This factor structure differs from the four-subscale FGC Objectives scale on which the current measure is based (Pennell, 2004, 2006). The primary difference is that the questions specific to family members attending the meeting (who, how many, and the ratio to professionals) loaded on a separate factor whereas in the FGC objectives scale these items loaded on the Cultural Safety and Family Leadership subscale factors. Similarly, in these analyses, the professional roles and behavior loaded on a single factor, whereas in the FGC objectives scale they were included in all of the subscales. These differences may be due to changing the language, the timing of the surveys at the end of the conference versus a month later, the self-administration method, or the fact that multiple participants completed the measure.

This proposed structure provides straightforward guidance to monitoring fidelity in public child welfare systems. Public child welfare systems can assess and report on the preparation process, the family attendance, and the behavior of professionals in the conference. While the measure is principle-based, the results are "actionable" if reporting is based on these factors. For example, concrete steps to change curriculum and training, to clarify professional roles, and to monitor facilitation could be taken if the results suggest that professionals are exhibiting difficulties in this area. Rather than the professionals making assumptions, this measure offers a clear way of asking participants what happened before, during, and at the end of the meeting, who was there, and how the professionals engaged with the family and interacted with the group. This feedback is particularly critical in Pennsylvania, a county-administered state with variation in the maturity and delivery of FGDM. As such, if child welfare agencies do not incorporate model fidelity measurement into standard practice, then there are limited opportunities for improving practices and building the evidence of the impact of FGDM. Finally, the FGDM-MFS can be used to support the professionals who deliver and champion FGDM in embracing a more objective analysis of FGDM outcomes. As evidenced by the process of refining the fidelity measure described in this study, professionals who believe in its impact may also be protective of the practice and reluctant to endorse routine measurement of fidelity and effectiveness. Through the process of routine monitoring, a commitment to ongoing practice improvement is more likely to occur than when monitoring is done sporadically or in response to funders.

This study also illustrates how to refine an instrument originally based on principles so that it can be understood by a range of participants and broadly distributed and managed with limited administrative support. In spite of revisions in wording and change in administration method, this measure remains grounded in the nine principles proposed by Pennell, (1999). As research in this area proceeds, it will be important to combine fidelity to outcome data in order to determine which aspects of the model produce positive outcomes. For example, research conducted on Team Decision Making, a teaming intervention used in child welfare, found that relative attendance at the meetings correlated with increased relative placement, as did the presence of birth parents with reunifications when parents were at meetings (Crampton, Usher, Wildfire, Webster, \& Cuccaro-Alamin, 2011). Stuczynski and Kimmich (2010) found that keeping to timelines was negatively associated with having a range of attendees (p. 419). Both findings illustrate that determining the processes that must be implemented and those that can be adapted or not included without reducing the effectiveness could help to increase the efficiency of FGDM (Crampton, 2007).

As research in FGDM fidelity proceeds, it will be critical to include multiple assessments of fidelity in a planned and comprehensive approach. Although this measure represents a step towards a tool and a process that can be used in systems where there are limited resources, it does not replace other approaches of assessing fidelity. 
No one measure or method will give a comprehensive picture. Combining this measure with purposively selected record reviews, personal interviews, and observation of groups would provide a more complete understanding of how FGDM is being implemented and whether it results in positive changes in safety, permanence and well-being. Qualitative data would help to explain the reasons for the level of agreement and divergences among youth, families, and professionals and between individuals of different races (Rauktis et al., 2011a). The FGDM-MFS encompasses the preparations and conference itself but not the post-meeting work of carrying out the plan or revising it in response to changing circumstances. Reviewing records and talking with families would help determine if the plan is being carried out.

The results and implications must be considered in the context of the following limitations. One is that this is a self-administered instrument completed right at the end of the conference when participants lack the time to reflect on the process. Limitations in the sample are also present. Participation in the survey was voluntary, and it is possible that some individuals opted to not participate. Missing data were a problem; more troublesome, however, was the response set and the non-normality of the distribution. Although this was managed in the analyses, it begs the question of whether to reverse word items so that respondents may be less likely to endorse the same rating for all items. On the other hand, doing this would increase the difficulty for individuals who have limited literacy skills, creating the potential for error.

Despite these limitations, the results from this study provide valuable guidance to practitioners and policymakers about the importance of attending to multiple perspectives in assessing program delivery. The experience in Pennsylvania supports the feasibility of incorporating model fidelity measurement into standard practice and lays the foundation for building the evidence on the impact of FGDM for diverse groups.

\section{Acknowledgments}

This research was funded by the Pennsylvania Office of Children Youth and Families, and the University of Pittsburgh, School of Social Work, Child Welfare Resource Center. The authors wish to acknowledge the following individuals for their assistance in this study and in preparing the manuscript: Helen Cahalane, Ph.D., Andrea Richardson, Susan Antonacci, Shauna Reinhart, Ilsung Nam, Ph.D., Katie Greeno, Ph.D., Gary Koeske, Ph.D., and Julia Scanlon.

\section{References}

American Humane Association, \& FGDM Guidelines Committee (2010). Guidelines fo family group decision making in child welfare. Englewood, CO: Author. (Retrieved from http://www.americanhumane.org/assets/pdfs/children/fgdm/guidelines.pdf

Barth, R. P. (2002). In Gail Buford, \& Joe Hudson (Eds.), Family group conferencing: New directions in community-centered child and family practice. Journal of Sociology E Social Welfare, 29(3). (pp. 199-201).

Bell, M., \& Wilson, K. (2006). Children's views of family group conferences. British Journal of Social Work, 36(4), 671-681.

Bentler, P. M. (1990). Comparative fit indexes in structural models. Psychological Bulletin, $107(2), 238-246$

Berzin, S. C. (2006). Using sibling data to understand the impact of family group decision-making on child welfare outcomes. Children and Youth Services Review, 28(12), 1449-1458.

Berzin, S. C., Thomas, K. L., \& Cohen, E. (2007). Assessing model fidelity in two family group decision-making programs: Is this child welfare intervention being implemented as intended? Journal of Social Service Research, 34(2), 55-71.

Breitenstein, S. M., Gross, D., Garvey, C. A., Hill, C., Fogg, L., \& Resnick, B. (2010). Implementation fidelity in community-based interventions. Research in Nursing and Health, 33(2), 164-173.

Bruns, E. J., Burchard, J. D., Suter, J. C., Leverentz-Brady, K., \& Force, M. M. (2004) Assessing fidelity to a community-based treatment for youth: The Wraparound Fidelity Index. Journal of Emotional and Behavioral Disorders, 12(2), 79-89.

Bruns, E. J., Suter, J. C., Force, M. M., \& Burchard, J. D. (2005). Adherence to wraparound principles and association with outcomes. Journal of Child and Family Studies, 14(4), 521-534.

Burford, G., Connolly, M., Morris, K., \& Pennell, J. (2010). Annotated bibliography on engaging the family group in child welfare decision making. (2010/original 2009). Englewood, CO: American Humane Association. (Available at: http://www.americanhumane.org/ children/professional-resources/program-publications/family-group-decision-making/ bibliographies.html)

Burford, G., Pennell, J., \& Edwards, M. (2011). Family team meetings as principled advocacy. Journal of Public Child Welfare, 5(2-3), 318-344.

Cattell, R. B. (1966). The scree test for the number of factors. Multivariate Behavioral Research, 1(2), 245-276.

Century, J., Rudnick, M., \& Freeman, C. (2010). A framework for measuring fidelity of implementation: A foundation for shared language and accumulation of knowledge. American Journal of Evaluation, 31(2), 199-218.

Crampton, D. S. (2007). Research review: Family group decision-making: a promising practice in need of more programme theory and research. Child E Family Social Work, 12(2), 202-209.

Crampton, D. S., \& Jackson, W. L. (2007). Family group decision making and disproportionality in foster care: A case study. Child Welfare, 86(3), 51-69.

Crampton, D. S., Usher, G. L., Wildfire, J. B., Webster, D., \& Cuccaro-Alamin, S. (2011) Does community and family engagement enhance permanency for children in foster care? Findings from an evaluation of the family-to-family initiative. Child Welfare, 90(4), 61-78.

Crea, T. M., \& Berzin, S. C. (2009). Family involvement in child welfare decision-making: Strategies and research on inclusive practices. Journal of Public Child Welfare, 3(3), 305-327.

Crea, T. M., Crampton, D. S., Abramson-Madden, A., \& Usher, C. L. (2008). Variability in the implementation of team decisionmaking (TDM): scope and compliance with the family to family practice model. Children and Youth Services Review, 30(11), 1221-1232.

Fixsen, D. L., Naoom, S. F., Blasé, K. A., Friedman, R. M., \& Wallace, F. (2005). Implementation research: A synthesis of the literature. The National Implementation Research Network (FMHI Publication \#231). Tampa, FL: University of South Florida, Louis de la Parte Florida Mental Health Institute.

Hall, G. E., \& Hord, S. M. (1987). Change in schools: Facilitating the process. Albany, NY: State University of New York Press.

Hassall, I. (1996). Origin and development of family group conferences. In J. Hudson, A Morris, G. Maxwell, \& B. Galaway (Eds.), Family group conferences: Perspectives on policy and practice (pp. 17-36). Monsey, NY: Willow Tree Press.

Hayes, S. C. (1998). President's message: Dissemination research now. The Behavior Therapist, 21(9), 166-169.

Henggeler, S. W., Borduin, C. M., Schoenwald, S. K., Huey, S. J., \& Chapman, J. E. (2006) Multisystemic Therapy Adherence Scale-Revised (TAM-R). Unpublished instrument. Charleston: Department of Psychiatry and Behavioral Sciences, Medical University of South Carolina.

Henggeler, S. W., Melton, G. B., Brondino, M. J., Scherer, D. G., \& Hanley, J. H. (1997) Multisystemic therapy with violent and chronic juvenile offenders and their families: The role of treatment fidelity in successful dissemination. Journal of Consulting and Clinical Psychology, 65(5), 821-833.

Henggeler, S. W., Schoenwald, S. K., Borduin, C. M., Rowland, M. D., \& Cunningham, P. B. (1998). Multisystemic treatment of antisocial behavior in children and adolescents. New York: Guilford.

Kaye, S., \& Osteen, P. J. (2011). Developing and validating measures for child welfare gencies to self-monitor fidelity to a child safety intervention. Children and Youth Services Review, 33(11), 2146-2151.

McHugo, G. J., Drake, R. E., Teague, G. B., \& Xie, H. Y. (1999). Fidelity to assertive community treatment and client outcomes in the New Hampshire dual disorders study. Psychiatric Services, 50(6), 818-824.

Merkel-Holguin, L., \& Wilmot, L. (2005). Analyzing family involvement approaches. In J. Pennell, \& G. Anderson (Eds.), Widening the circle: The practice and evaluation of family group conferencing with children, youths, and their families (pp. 183-201). Washington, DC: NASW Press.

Mowbray, C. T., Holter, M. C., Teague, G. B., \& Bybee, D. (2003). Fidelity criteria: Development, measurement, and validation. American Journal of Evaluation, 24(3), 315-340.

Pennell, J. (2003a). Achievement of objectives, pre and during conference. Raleigh, NC: North Carolina State University, Department of Social Work.

Pennell, J. (2003b). Are we following key FGC practices? Views of conference participants. Protecting Children, $18(1 \& 2), 16-21$

Pennell, J. (2004). Family group conferencing in child welfare: Responsive and regulatory interfaces. Journal of Sociology \& Social Welfare, 31(1), 117-135.

Pennell, J. (2005). Checking for model fidelity. In J. Pennell, \& G. Anderson (Eds.), Widening the circle: The practice and evaluation of family group conferencing with children, youths, and their families (pp. 107-121). Washington, DC: NASW Press.

Pennell, J. (2006). Stopping domestic violence or protecting children? Contributions from restorative justice. In D. Sullivan, \& L. Tifft (Eds.), Handbook of restorative justice: A global perspective (pp. 286-298). New York: Routledge.

Pennell, J. (2009). Widening the circle: Countering institutional racism in child welfare. In S. Strega, S. A. Esquao, \& J. Carrière (Eds.), Walking this path together: Anti-racist and anti-oppressive child welfare practice (pp. 78-95). Halifax, Nova Scotia, \& Winnipeg Manitoba: Fernwood.

Pennell, J., \& Anderson, G. (Eds.). (2005). Widening the circle: The practice and evaluation of family group conferencing with children, youths, and their families. Washington, DC: NASW Press.

Pennell, J., \& Burford, G. (1995). Family group decision making: New roles for 'old' partners in resolving family violence: Implementation Report (Vols. I-II). St. John's, NF: Memorial University of Newfoundland, School of Social Work.

Pennell, J., \& Burford, G. (2000). Family group decision making: Protecting children and women. Child Welfare, 79(2), 131-158.

Pennell, J., Burford, G., Connolly, M., \& Morris, K. (2011). Introduction: Taking child and family rights seriously: Family engagement and its evidence in child welfare. Child Welfare, 90(4), 9-18.

Pennell, J., Edwards, M., \& Burford, G. (2010). Expedited family group engagement and child permanency. Children and Youth Services Review, 32, 1012-1019. 
Pennell, J. (with the assistance of Hardison, J., \& Yerkes, E.). (1999). North Carolina Family Group Conferencing Project: Building partnerships with and around families: Report to the North Carolina Division of Social Services, Fiscal year 1998-1999. Raleigh: North Carolina State University, Social Work Program, North Carolina Family Group Conferencing Project.

Proctor, E., Silmere, H., Raghavan, R., Hovmand, P., Aarons, G., Bunger, A., et al. (2011). Outcomes for implementation research: Conceptual distinctions, measurement challenges, and research agenda. Administration and Policy in Mental Health and Mental Health Services Research, 38(2), 65-76.

Rangihau, J. (1986). Puao-te-Ata-tu (Daybreak): Report of the Ministerial Advisory Committee on a Maori perspective for the Department of Social Welfare. Wellington, New Zealand: Department of Social Welfare, Government Printing Office.

Rast, J., Peterson, C., Earnest, L., \& Mears, S. L. (2003). Service process as a determinant of treatment effect: The importance of fidelity. Paper presented at the 16th Annual Research Conference Proceedings, a System of Care for Children's Mental Health: Expanding the Research Base, Tampa, FL.

Rauktis, M. E. (2008). Family group decision making: A profile of practices in Pennsylvania 2008. University of Pittsburgh, Child Welfare Training Program. Retrieved August 22, 2012 from http://www.pacwcbt.pitt.edu/organizational\%20effectiveness/fgdm\% 20evaluation\%20pdfs/final\%20report\%20-\%20fgdm\%20survey.pdf

Rauktis, M. E., Huefner, J., \& Cahalane, H. (2011a). Perceptions of fidelity to family group decision-making principles: Examining the impact of race, gender, and relationship. Child Welfare, 90(4), 41-59.

Rauktis, M. E., Pennell, J., Burford, G., Crampton, D., \& Merkel-Holguin, L. (2012). Measuring fidelity of various family engagement approaches: Past, present, future. Paper presented at the 2012 American Humane Association Family Engagement Conference, Orlando, FL.

Rauktis, M. E., Pennell, J., \& Reinhart, S. (2011b). Evaluation of family group decision making: Strengthening practice through measuring and monitoring fidelity. Paper presented at the National Child Welfare Evaluation Summit, Washington, DC.

Rotabi, K. S., Pennell, J., Roby, J. L., \& Bunkers, K. M. (2012). Family group conferencing as a culturally adaptable intervention: Reforming intercountry adoption in Guatemala. International Social Work, 55(3), 402-416. http://dx.doi.org/10.1177/0020872812437229.

Satorra, A., \& Bentler, P. M. (1988). Scaling corrections for chi-square statistics and covariance structure analysis. ASA 1988 Proceedings of the Business and Economic Statistics Section (pp. 308-313). Alexandria, VA: American Statistical Association.

Satorra, A., \& Bentler, P. M. (1994). Corrections to test statistics and standard errors in covariance structure analysis. In A. von Eye, \& C. C. Clogg (Eds.), Latent variables analysis: Applications for developmental research (pp. 399-419). Thousand Oaks, CA: Sage.
Schoenwald, S. K., Garland, A. F., Chapman, J. E., Frazier, S. L., Sheidow, A. J., \& Southam-Gerow, M. A. (2011). Toward the effective and efficient measurement of implementation fidelity. Administration and Policy in Mental Health and Mental Health Services Research, 38(1), 32-43.

Schoenwald, S. K., Henggeler, S. W., Brondino, M. J., \& Rowland, M. D. (2000). Multisystemic therapy: Monitoring treatment fidelity. Family Process, 39(1), 83-103.

Sheets, J., Wittenstrom, K., Fong, R., James, J., Tecci, M., Baumann, D. J., et al. (2009). Evidence-based practice in family group decision-making for Anglo, African American and Hispanic families. Children and Youth Services Review, 31(11), 1187-1191.

Shlonsky, A., Schumaker, K., Cook, C., Crampton, D., Saini, M., Backe-Hansen, E., et al. (2009). Family group decision making for children at risk of abuse and neglect. Cochrane Database of Systematic Reviews, 3(1-33).

Sieppert, J. D., Hudson, J., \& Unrau, Y. (2000). Family group conferencing in child welfare: Lessons from a demonstration project. Families in Society: The Journal of Contemporary Human Services, 81(4), 382-391.

Stevens, J. (1996). Applied multivariate statistics for social sciences. Mahwah, NJ: Lawrence Erlbaum Associates.

Stuczynski, A., \& Kimmich, M. H. (2010). Challenges in measuring the fidelity of a child welfare service intervention. Journal of Public Child Welfare, 4(4), 406-426 (Article).

Sundell, K., \& Vinnerljung, B. (2004). Outcomes of family group conferencing in Sweden: A 3-year follow-up. Child Abuse \&' Neglect, 28(3), 267-287.

Teague, G. B., Bond, G. R., \& Drake, R. E. (1998). Program fidelity in assertive community treatment: Development and use of a measure. The American Journal of Orthopsychiatry, 68(2), 216-232.

United Nations, General Assembly (September 13). Declaration on the rights of indigenous peoples. Geneva, Switzerland: 107th Plenary Meeting. Retrieved June 30, 2009, from http://www.un.org/esa/socdev/unpfii/documents/DRIPS_en.pdf

Convention on the rights of the child. Retrieved September 29, 2012. http://www2. ohchr.org/english/law/pdf/crc.pdf. (1989).

Vesneski, W., \& Kemp, S. P. (2000). Family group conferencing in Washington State. In G. Burford, \& J. Hudson (Eds.), Family group conferences: Perspectives on policy, practice, and research (pp. 312-323). New York: Aldine de Gruyter.

Weigensberg, E. C., Barth, R. P., \& Guo, S. (2009). Family group decision making: A propensity score analysis to evaluate child and family services at baseline and after 36-months. Children and Youth Services Review, 31(3), 383-390. 